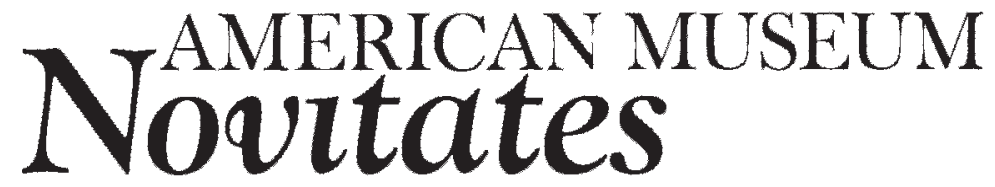

PUBLISHED BY THE AMERICAN MUSEUM OF NATURAL HISTORY CENTRAL PARK WEST AT 79TH STREET, NEW YORK, NY 10024 Number 3648, 14 pp., 4 figures, 2 tables

June 25, 2009

\title{
A Large Alvarezsaurid from the Late Cretaceous of Mongolia
}

\author{
ALAN H. TURNER, ${ }^{1,2}$ STERLING J. NESBITT, ${ }^{2,3}$ AND MARK A. NORELL ${ }^{2}$
}

\begin{abstract}
We report a new alvarezsaurid, Kol ghuva, from the Late Cretaceous of Mongolia that demonstrates that the clade was not restricted to small taxa $(\sim 3-15 \mathrm{~kg})$. The specimen was found at the Ukhaa Tolgod locality, which has previously produced only a single diminutive alvarezsaurid, Shuvuuia deserti. Although known only from a well-preserved right foot, the new taxon is diagnosable by the following combination of characters: extensor grooves on digit IV phalanges; robust flexor tubercle on pedal unguals; MT III does not reach ankle; accessory dorsomedial flange absent on the medial side of the distal end of the MT II; MT II shorter than MT IV; and MT III extends higher proximally than other alvarezsaurids (more than $1 / 2$ total metatarsus length). The new taxon provides additional insight into the diversity of this clade and the dinosaurian assemblage of Ukhaa Tolgod.
\end{abstract}

\section{INTRODUCTION}

Alvarezsaurids have been recognized only relatively recently as a distinct group of theropod dinosaurs (Bonaparte, 1991; Perle et al., 1993; Novas, 1996, 1997; Chiappe et al., 1996, 1998; Hutchison and Chiappe, 1998). Alvarezsaurids, especially the Mongolian forms, are very unusual dinosaurs. They have short, but powerful forelimbs with a single large claw and two lateral diminutive fingers (digits II and III), the teeth are tiny, and the fragile skull was likely kinetic (Chiappe et al., 1998). Immunological evidence provides confirmation that they were feathered (Schweitzer et al., 1999) as supported by phylogenetic bracketing within maniraptoran theropods (see Turner et al., 2007). Many characteristics (e.g., the presence of a keeled sternum, lack of a pubic symphysis, the fusion of carpal elements into a

\footnotetext{
${ }^{1}$ Department of Anatomical Sciences, Stony Brook University, Health Science Center, T8 (040), Stony Brook, NY 11794 (alan.turner@stonybrook.edu).

${ }_{2}^{2}$ Division of Paleontology, American Museum of Natural History, Central Park West at 79th St. New York, NY 10024.

${ }^{3}$ Lamont-Doherty Earth Observatory, Columbia University, 61 Rt. 9W, Palisades, NY 10964.
} 
carpometacarpal block, etc.) are quite similar to those of avialans, but appear to be convergent. These similarities have created confusion regarding the phylogenetic position of this unusual group. Variously they have been considered to be within Avialae (Perle et al., 1993), the sister-group of Avialae (Chiappe et al., 2002), the sister-group of ornithomimids (Sereno, 2001), and as basal maniraptoriforms (Xu et al., 2006; Turner et al., 2007).

Although they were first described in the Cretaceous of Patagonia (Bonaparte, 1991; Novas, 1997; Martinelli and Vera, 2007) and partial remains have been recovered in Late Cretaceous sediments of North America (Hutchison and Chiappe, 1998) and possibly Europe (Naish and Dyke, 2004), they have been most often found in the Late Cretaceous of central Asia. The first recognized Asian alvarezsaurid, Mononykus olecranus (Perle et al., 1993) comes from Late Cretaceous rocks at Bugin Tsav. It remains known from only the holotype (IGM 107/6) and was described in detail by Perle et al. (1994). Multiple specimens of the Campanian alvarezsaurid Shuvuuia deserti have since been collected (Chiappe et al., 1998, 2002; Suzuki et al., 2002) from a variety of localities. The monotypic Parvicursor remotus (Karhu and Ratian, 1996) comes from the Late Cretaceous (?Campanian) Mongolian locality of Khulsan. A single alvarezsaurid fibula has been reported from the Late Cretaceous Iren Dabasu Formation in northern China (Chiappe et al., 2002). Longrich and Currie (2009) consider some of the Tugriken Shireh specimens described by Chiappe et al. (2002) and Suzuki et al. (2002) to be juvenile Shuvuuia deserti to instead be a new taxon. To date, these are the only taxa described from Asia.

Even though alvarezsaurids are known from several specimens on three continents (Eurasia, South America, and North America), much about their anatomy is difficult to determine because of the paucity of remains. Shuvuuia deserti stands alone as the only alvarezsaurid known from well-preserved material, including complete skulls. Fortunately, growth series are also known for this taxon (Chiappe et al., 2002), because all other described alvarezsaurids are known from unique specimens.

Here, we expand the diversity of alverezsaurids and describe a new specimen from the
Late Cretaceous of Mongolia, which represents a new alvarezsaurid taxon. This unique specimen (IGM 100/2011, field number MAE $00-45)$ is represented by a complete articulated left pes from the Ukhaa Tolgod locality (Dashzeveg et al., 1995; Dingus et al., 2008) in the south central Gobi Desert.

The institutional acronyms used throughout this work are in appendix 1.

\section{SYSTEMATIC PALEONTOLOGY}

THEROPODA MARSH, 1881

COELUROSAURIA VON HUENE, 1914

MANIRAPTORA GAUTHIER, 1986

ALVAREZSAURIDAE BONAPARTE, 1991

Kol ghuva, new taxon

Holotype: IGM 100/2011. Complete pes including an indeterminate distal tarsal, metatarsals I, II, III, IV with a complete complement of pedal digits and a partial metatarsal V.

EтумоLogy: From Mongolian köl, "foot" (http://www.linguamongolia.co.uk/cgi-bin/search Db3.pl?search_param $=$ foot\&cmdSubmit $=$ Search\&langselect $=$ english) + ghuv- $a$, "beautiful" (http://www.linguamongolia.co.uk/cgi-bin/ searchDb3.pl?search_param $=$ beautiful\&cmd Submit $=$ Search\&langselect $=$ english) .

LocAliTY: Ukhaa Tolgod. Ömnögov Aimag, Mongolia (Dashzeveg et al., 1995). Within the Ankylosaur Flats locality (Dingus et al., 2008), IGM 100/2011 was found at the Big Mamma sublocality.

Diagnosis: This alvarezsaurid is diagnosed by the following unique combination of characters: extensor grooves on digit IV phalanges; robust flexor tubercle on pedal unguals; MT III does not reach ankle; accessory dorsomedial flange absent on the medial side of the distal end of the MT II; MT II shorter than MT IV; MT III extends higher up the metatarsus than other alvarezsaurids (greater than $1 / 2$ metatarsus length).

\section{DESCRIPTION}

The holotype specimen of IGM 100/2011 consists of a complete right metatarsus and pes along with a single distal tarsal (figs. 1-4). The 


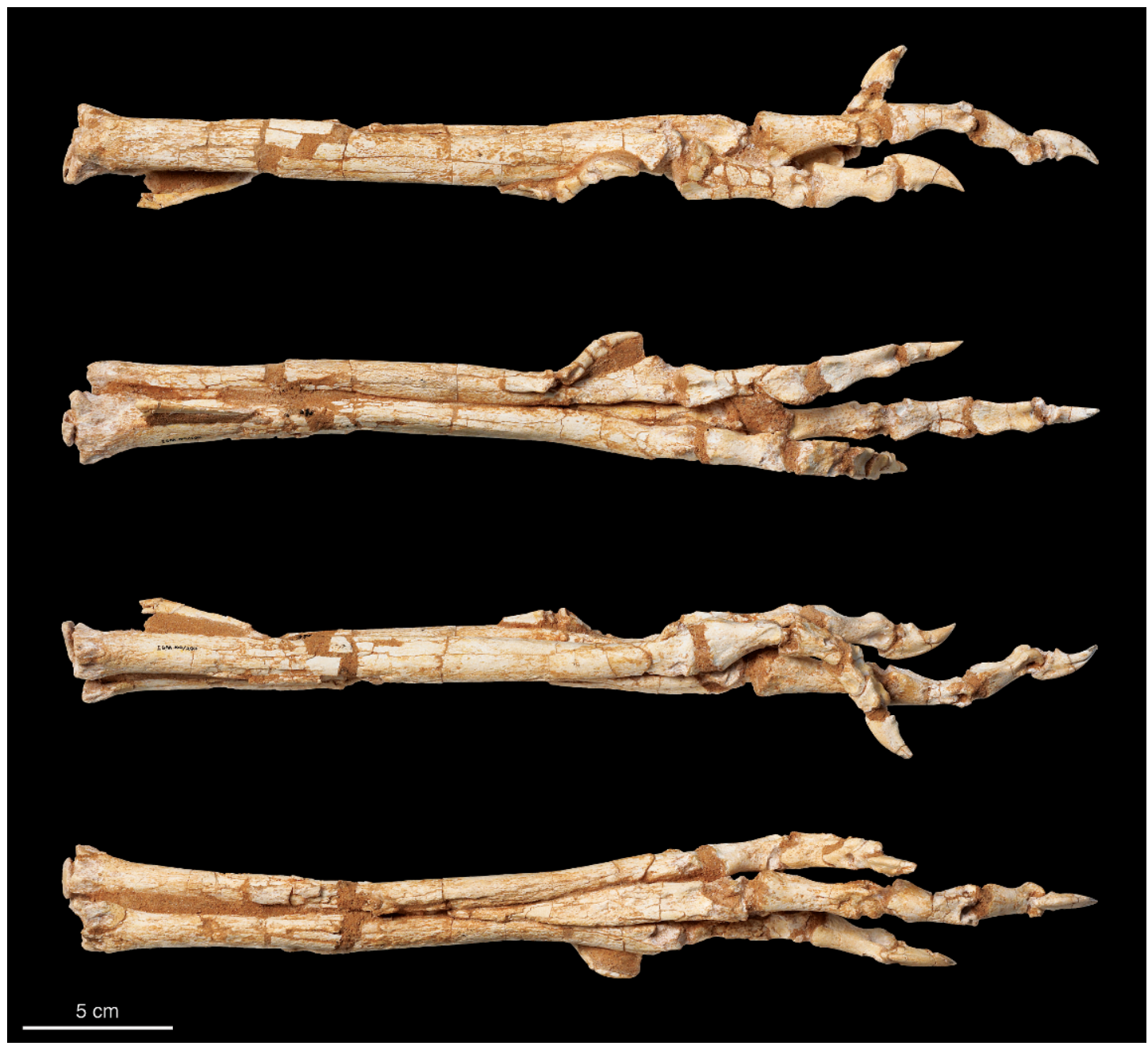

Fig. 1. The holotype specimen of Kol ghuva (IGM 100/2011).

specimen was found articulated and isolated from other skeletal elements. As is typical of most theropods, the foot is tridactyl, with a small metatarsal I (MT I) adhering to the posteromedial shaft of MT II distally and a splintlike MT V which extends only $1 / 3$ of the way distally from the ankle along the MT IV shaft. Just proximal to midshaft, the metatarsus is broken and slightly crushed, but not so much to significantly influence shape or length measurements. In general form, the pes of $\mathrm{Kol}$ ghuva is very elongated and gracile exhibiting an extreme arctometatarsalian condition as in other Mongolian alvarezsaurids. MT III proximally tapers dramatically only halfway up the metatarsus (fig. 3). The metatarsus (proximal edge metatarsals II and IV to the distal extent of metatarsal III) measures $225 \mathrm{~mm}$ in length making Kol ghuva the largest alvarezsaurid known (table 1). Proximally, only metatarsal II and IV meet the tarsals. Metatarsals II and IV contact each other along a nearly straight proximodistal line. Each metatarsal contributes equally to the proximal portion of the metatarsus. As indicated above, there is no evidence that metatarsal III reached the proximal end of the metatarsus near the ankle joint, this is present only in alvarezsaurids more derived than Alvarezsaurus calvoi and Patagonykus puertai (Chiappe et al., 1998, 2002). The 

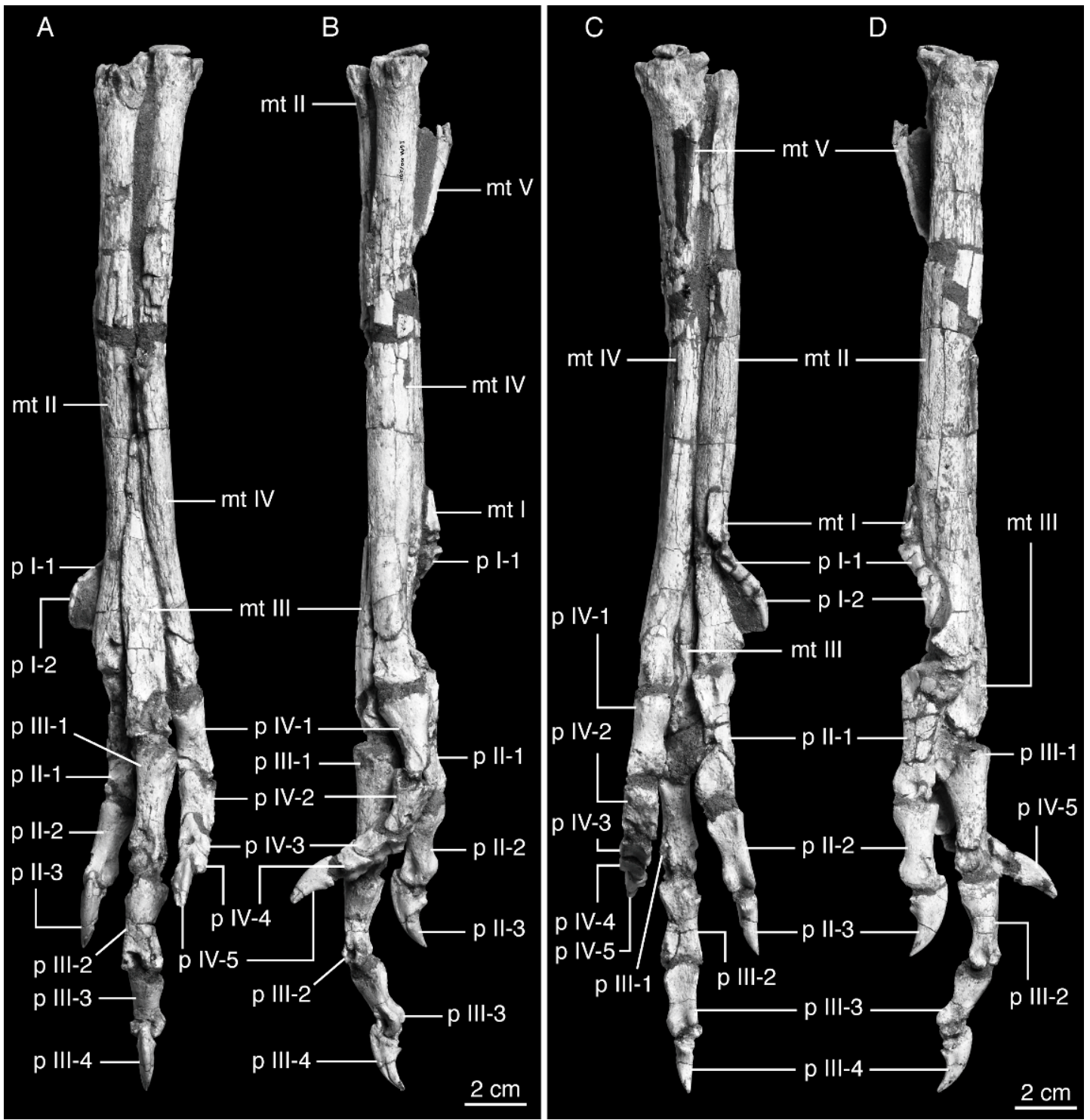

Fig. 2. Metatarsus and pes of Kol ghuva (IGM 100/2011). A. Anterior view. B. Lateral view. C. Posterior view. D. Medial view. Abbreviations: dt, distal tarsal; mt, metatarsal; p, phalanx.

phalangeal formula of Kol ghuva, 2-3-4-5-0, is consistent with the typical theropod formula. Measurements of individual elements are given in table 2.

A small ovoid distal tarsal lies atop the posterior margin of MT IV (fig. 4). It is thickest along its posterior margin, thinning anteriorly and medially. The dorsal surface is slightly convex and it is clear that the tarsal was not fused to the metatarsus. The identity of this tarsal element is difficult to determine. Most theropods have two distal tarsals (Norell and Makovicky, 1999); however, in all alvarezsaurids that preserve this region (Patagonykus puertai MCF PVPH-37, Shuvuuia deserti IGM 100/1001, and Parvicursor remotus [Karhu and Rautian, 1996]) only a single ovoid element is present (Chiappe et al., 2002). As in other Asian alvarezsaurids, the distal tarsal lies on the distal (plantar) border of metatarsal IV, as opposed to 


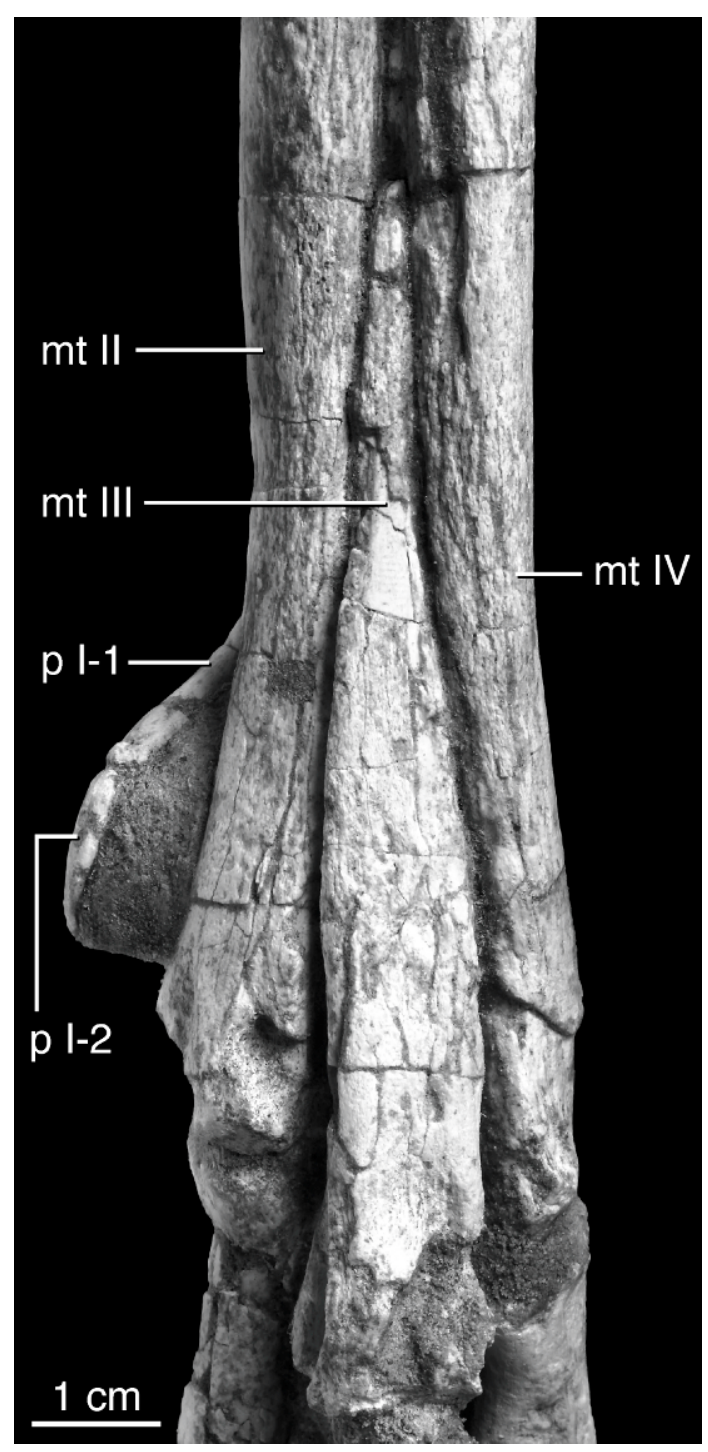

Fig. 3. Metatarsus of Kol ghuva (IGM 100/ 2011) in anterior view showing the pinched metatarsal III. Abbreviations: mt, metatarsal; p, phalanx.

the condition in Patagonykus puertai where the distal tarsal coossifies to metatarsals II and IV (MCF PVPH 37; Novas, 1997)

Digit I is seemingly in life position, with an unreversed hallux. Interestingly, the articulation of MT I to the metatarsus is posterolateral to the anterior face of the MT 2 and digit I seemingly curls around the metatarsus to achieve a directly anterior orientation. Metatarsal I is a short element affixed to the

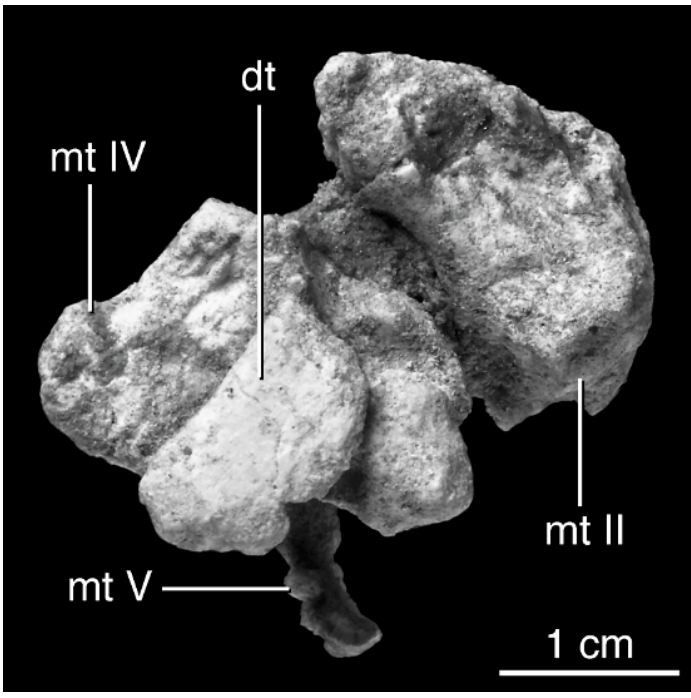

Fig. 4. Proximal view of the ankle joint showing the position of the distal tarsal, which lie unfused atop MT IV. Abbreviations: dt, distal tarsal; mt, metatarsal.

posterior shaft of MT II as in most other theropods. It is located approximately $2 / 3$ the way distal on this shaft, and is fairly straight, unlike the familiar "J" shape present in avialans. The articular condyle is subtriangular in cross-section and the flexor pits are small, shallow depressions that converge posteriorly. The anterior margins of the condyle cannot be described because the medial surface is poorly preserved and the lateral surface is affixed to the shaft of MT II.

Phalanx I-1 is twice the length of MT I and is well preserved, yet broken (with no displacement) along its shaft. Proximally, the medial half of the articular condyle is damaged, although it is clear that strong parallel ridges define a shallow flexor depression on the proximoventral surface of the phalanx. Distally, a large collateral ligament pit is present on the medial surface. The lateral surface is not exposed. Phalanx I-2 (the ungual) is short and weakly curved as in other alvarezsaurids. The articular surface is fairly deep whereas the dorsal process extends farther distally than the ventral one. A flexor tubercle is not present and the medial surface possesses a deep claw-sheath groove that extends from the midpoint of the digit to the distal point of the phalanx. 


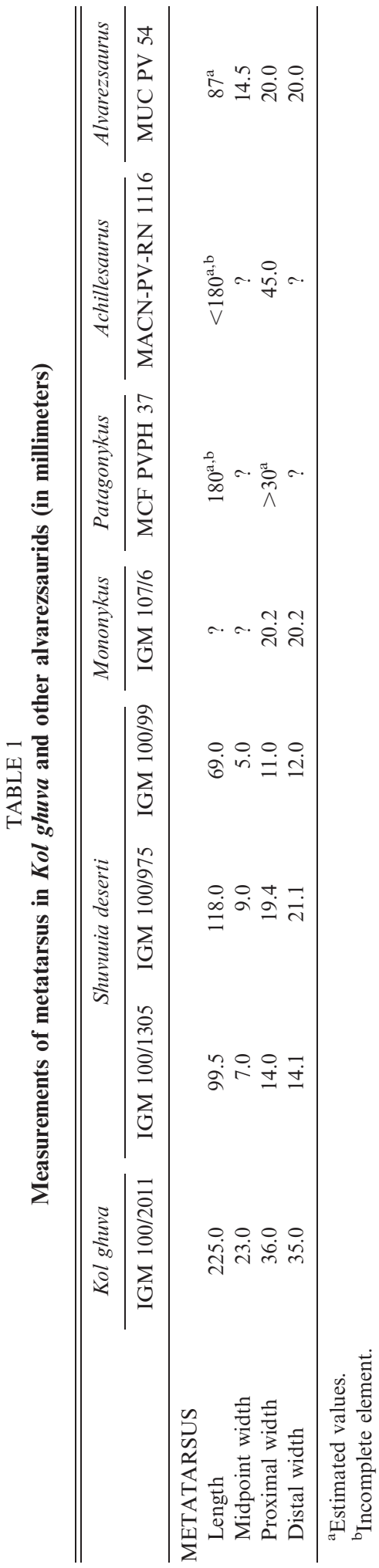

TABLE 2

Measurements of Foot in Kol ghuva (in millimeters)

\begin{tabular}{|c|c|}
\hline & IGM 100/2011 \\
\hline & left \\
\hline \multicolumn{2}{|l|}{ METATARSALS } \\
\hline \multicolumn{2}{|l|}{ Metatarsal I } \\
\hline Length & 17.0 \\
\hline Distal depth & 4.4 \\
\hline Distal transverse width & 6.1 \\
\hline \multicolumn{2}{|l|}{ Metatarsal II } \\
\hline Length & 203.5 \\
\hline Distal transverse width & 16.2 \\
\hline Distal depth & 15.1 \\
\hline Proximal transverse width & 14.0 \\
\hline Proximal depth & 24.0 \\
\hline \multicolumn{2}{|l|}{ Metatarsal III } \\
\hline Length & 109.0 \\
\hline Distal transverse width & 15.1 \\
\hline Distal depth & 15.7 \\
\hline Proximal transverse width & - \\
\hline Proximal depth & - \\
\hline \multicolumn{2}{|l|}{ Metatarsal IV } \\
\hline Length & 208.1 \\
\hline Distal transverse width & 12.0 \\
\hline Distal depth & 18.0 \\
\hline Proximal transverse width & 18.0 \\
\hline Proximal depth & 23.0 \\
\hline \multicolumn{2}{|l|}{ Metatarsal V } \\
\hline Length & $63^{\mathrm{a}, \mathrm{b}}$ \\
\hline Diameter & 4 \\
\hline \multicolumn{2}{|l|}{ PHALANGES } \\
\hline \multicolumn{2}{|l|}{$\mathrm{I}-1$} \\
\hline Length & 21.7 \\
\hline Distal transverse width & 5.8 \\
\hline Proximal transverse width & 6.0 \\
\hline Proximal height & 6.1 \\
\hline Distal Height & 6.0 \\
\hline \multicolumn{2}{|l|}{$\mathrm{I}-2$} \\
\hline Proximal transverse width & 4.0 \\
\hline Proximal height & 7.6 \\
\hline Facet height & 6.0 \\
\hline \multicolumn{2}{|l|}{ II-1 } \\
\hline Length & 44.0 \\
\hline Distal transverse width & 13.5 \\
\hline Proximal transverse width & 14.5 \\
\hline Proximal height & 19.0 \\
\hline Distal height & 11.9 \\
\hline \multicolumn{2}{|l|}{ II-2 } \\
\hline Length & 29.9 \\
\hline Distal transverse width & 10.0 \\
\hline Proximal transverse width & 12.8 \\
\hline Proximal height & 14.0 \\
\hline Distal height & 12.0 \\
\hline
\end{tabular}


TABLE 2

(Continued)

\begin{tabular}{|c|c|}
\hline & IGM 100/2011 \\
\hline & left \\
\hline \multicolumn{2}{|l|}{ II-3 } \\
\hline Proximal transverse width & 7.1 \\
\hline Proximal height & 13.4 \\
\hline Facet height & 11.1 \\
\hline \multicolumn{2}{|l|}{ III-1 } \\
\hline Length & 43.2 \\
\hline Distal transverse width & $12.5^{\mathrm{a}, \mathrm{b}}$ \\
\hline Proximal transverse width & 15.0 \\
\hline Proximal height & 19.0 \\
\hline Distal height & 10.9 \\
\hline \multicolumn{2}{|l|}{ III-2 } \\
\hline Length & 31.2 \\
\hline Distal transverse width & 14.0 \\
\hline Proximal transverse width & 14.1 \\
\hline Proximal height & 13.9 \\
\hline Distal height & 9.0 \\
\hline \multicolumn{2}{|l|}{ III-3 } \\
\hline Length & 24.0 \\
\hline Distal transverse width & 10.8 \\
\hline Proximal transverse width & 12.0 \\
\hline Proximal height & 10.8 \\
\hline Distal height & 9.0 \\
\hline \multicolumn{2}{|l|}{ III-4 } \\
\hline Length along outer curvature & 24.1 \\
\hline Proximal transverse width & 6.6 \\
\hline Proximal height & 10.5 \\
\hline Facet height & 8.1 \\
\hline \multicolumn{2}{|l|}{ IV-1 } \\
\hline Length & 23.0 \\
\hline Distal transverse width & 13.1 \\
\hline Proximal transverse width & 12.0 \\
\hline Proximal height & 18.1 \\
\hline Distal height & $8^{\mathrm{b}}$ \\
\hline \multicolumn{2}{|l|}{ IV-2 } \\
\hline Length & 20.3 \\
\hline Distal transverse width & 12.0 \\
\hline Proximal transverse width & $12.0^{\mathrm{b}}$ \\
\hline Proximal height & 14.5 \\
\hline Distal height & 6.6 \\
\hline \multicolumn{2}{|l|}{ IV-3 } \\
\hline Length & 16.0 \\
\hline Distal transverse width & 11.0 \\
\hline Proximal transverse width & 10.9 \\
\hline Proximal height & 12.0 \\
\hline Distal height & 9.0 \\
\hline \multicolumn{2}{|l|}{ IV-4 } \\
\hline Length & 11.2 \\
\hline
\end{tabular}

TABLE 2

(Continued)

\begin{tabular}{lc}
\hline \hline & IGM $100 / 2011$ \\
\cline { 2 - 2 } & left \\
\hline Distal transverse width & 9.1 \\
Proximal transverse width & 9.0 \\
Proximal height & 10.9 \\
Distal height & 8.1 \\
IV-5 & \\
Length along outer curvature & 20.0 \\
Proximal transverse width & 7.0 \\
Proximal height & 10.0 \\
Facet height & 8.0 \\
\hline
\end{tabular}

${ }^{\mathrm{a}}$ Estimated values.

${ }^{\mathrm{b}}$ Incomplete element.

Digit 2, along with digits 3 and 4 form the main body of the pes as is typical of theropod dinosaurs. The shaft of MT II is nearly straight, flaring medially toward its distal extremity. The proximal half of the shaft is semicircular in cross-section with a flat lateral surface, which contacts MT IV. Distally, the shaft constricts laterally and becomes subrectangular in cross-section. In anterior view, a clear depression lies adjacent to contact with MT I and MT III. Just proximal to the articular condyle, the shaft flares medially, so that the articulation with the phalanges is projected medially. The anterior articular surface is subtriangular. This articulation is expanded from the main shaft of the metatarsus and the proximomedial surface overhangs the rest of the shaft. On this surface there is a flattened area that corresponds to a similar feature on MT IV. Posteriorly, the articular surface only slightly overhangs the shaft. The articular surface is nonginglymoid; however, posteriorly oriented parallel ridges diverge from the shaft to enlarge the articular surface. The more medial of these projects out from the shaft and forms the posterior and ventral surface of the shallow ill-defined collateral ligament pit.

Phalanx II-1 is subequal in size to phalanx III-1, the two largest phalanges in the pes. It is roughly symmetrical except for the proximal articular region, which has a deep flexor pit on the ventral surface. This pit is defined by two ridges that extend from the main body of the 
phalanx, the medial of which is much thinner, forming a reflected winglike structure. The proximal surface is about twice the height of the distal condyle. Although crushed, the shaft shows little constriction between anterior and posterior articulation surfaces. Medially and laterally, the collateral ligament pits are deep and circular. The lateral collateral pit is considerable, about twice as deep as the medial pit. Dorsally, a shallow flexor pit lies just posterior to the bulbous articulation with phalanx II-2. The distal articulation is only slightly ginglymoid. Ventral and just posterior to the articular region lies a flat surface that graduates into a trough defined by shallow parallel ridges that form the articulation surface.

Unlike phalanx II-1, which is subtriangular in cross-section, phalanx II-2 is subrectangular in cross-section proximally grading into a subtriangular cross-section as it approaches the distal articular condyle, forming a small ridge on the proximodorsal surface. Ventrally, the medial flexor ridge is slightly more developed than its lateral counterpart. The space between the two is flat unlike the deep flexor pit present in phalanx II-1. In medial view, both dorsal and ventral components of the articular surface extend posteriorly to the same degree. The collateral ligament pits are visible in dorsal view owing to the subtriangular construction of the phalangeal shaft. The pits are oval and shallow and displaced dorsally almost to the dorsal margin of the phalanx. The articulation with phalanx II-3 (the ungual) is strongly ginglymoid as the result of the development of a pair of equally developed rounded ridges that form the articular condyle. These ridges extend on to the dorsal surface indicating a good degree of hyperflexion of the ungual.

Phalanx II-3, the ungual, is short and slightly trenchant. A sharp ridge forms the dorsal surface. The articular surface is much more extended dorsally than ventrally. A bulbous prominent flexor tubercle is present just ventral to the articular surface. The axis of the ungual is slightly skewed medially. In comparison with deinonychosaurs, there is an extensive, nearly flat ventral surface in $\mathrm{Kol}$ ghuva and other alvarezsaurids. The lateral and medial surfaces bear grooves, the medial of which is positioned more ventrally on ungual surface. Lateral grooves define an arc on the lateral surface; distally, it lies on the midline, but shifts ventrally proximally.

Metatarsal III shares many attributes typical of Asian alvarezsaurids, but also displays some clear differences. As in other extremely arctometatarsalian taxa (Avimimus, derived ornithomimids, and some troodontids), MT III is prominently exposed on the anterior surface of the metatarsus with little or no posterior exposure. If posterior exposure is present, it is small and lies distally between the flaring articular surfaces of MT II and MT IV. As in mononykine alvarezsaurids, the proximal tip of MT III does not reach the ankle (Chiappe et al., 2002). Instead, it terminates in the distal $1 / 3$ of MT II. This means that the wedge-shaped MT III lies on the surface of the metatarsus supported by the converging lateral surfaces of MT II and MT IV posteriorly. In general, lateral margins of the bone are subparallel, especially in contrast to Shuvuuia deserti where these margins diverge to form a flat sheet overlapping portions of MT 2 and MT 4 to a greater degree. Just proximal to MT III's widest dimension, it tapers to a point nested in the trough between MT II and MT IV. The distal articulation surface is not laterally expanded, although it is deeper than high. The dorsal surface is significantly expanded dorsally and lies in approximately the same plane as the surface of the metatarsal shaft, as in other alvarezsaurids. Although obscured by damage, there is evidence of a shallow extensor fossa just proximal to the articular surface. Laterally and medially an extensive but shallow collateral ligament pit (which lacks a distinct proximal margin) occupy nearly the entire lateral and medial surfaces. A similar condition is also found in Shuvuuia deserti (IGM 100/99), but not Mononykus olecranus (IGM 107/6). The distal articulation surface is smooth, simple, and mediolaterally symmetrical. The ventral surface is clearly pinched, forming a sinuous midline ridge that defines the contact surfaces with neighboring MT II and IV. Extensor ridges of the articular surface are low and rounded. No extensor depression is evident.

Phalanx III-1 is large as mentioned previously. The dorsal surface is flat, meeting the 
proximal articulation at a right angle. The phalanx thins distally giving the entire element an isosceles shape when viewed laterally. The proximal articulation surface is dorsoventrally convex with both dorsal and ventral margins equally developed. The phalanx broadens transversally just distal to the articular surface. Well-developed flexor ridges define a shallow flexor fossa on the posteroventral surface of the phalanx. The phalanx is waisted transversally between the anterior and posterior articular surfaces. The distal articular surface is wider than tall. Dorsally, there is a deep and anteroposteriorly extensive extensor depression; however, this may be accentuated by slight crushing. The lateral margin of this depression is defined by a small ridge that extends onto the lateral articular surface. Laterally, a deep, well-defined circular collateral ligament pit is present. The corresponding feature on the medial surface is not preserved. The ventral surface near the distal articular surface is nearly flat with faintly developed medial and lateral ridges extending onto the articular surface.

Phalanx III-2 is more robust than III-1 and is subtriangular in cross-section posteriorly along the shaft. When viewed laterally, it shows flexion where the shaft is slightly bow shaped, giving the ventral surface a longitudinally concave aspect. The proximal articular surface is subtriangular in shape. Dorsally, the articular surface overhangs phalanx III-1 more than the ventral articular margin. Laterally, the phalanx flares to an equal degree anterior to the articular surface. Ventrally, weakly developed extensor ridges define the medial and lateral border of the ventral surface of the phalanx. There is no distinct flexor depression between these ridges. As in the preceding phalanx, the shaft narrows transversally between the articular surfaces expanding again distally. The distal articulation surface is as wide as the proximal surface. The lateral and medial margins are flared as in phalanx I-2 so that the collateral ligament pits are visible in dorsal view. The lateral ligament pits are subcircular, equally developed in depth and dorsally displaced. There is some indication of an extensor depression dorsally in the form of a distinct rim extending posteriorly from the lateral extensor ridge.
The extent of this depression is indiscernible; however, there appears to be an arthropod burrow through the articular surface. Such burrows are a common aspect of the diagenesis of Ukhaa Tolgod vertebrate remains (Clark et al., 1999). Ventrally, the margins of the articular surface are defined by distinct, but shallow articular ridges.

Phalanx III-3 is generally similar to III-2 except in scale. The proximal articular shaft is subtriangular and the borders of the articular surface are subsymmetrical; however, the ventrolateral surface is slightly diminished compared to the medial surface. The entire ventral surface of the element is very flat to almost concave. The shaft narrows distally before broadening at the articular condyle. Compared to the preceding phalanx, the articulation is more ginglymoid as a result of a greater development of the trochlea. This trochlea is developed asymmetrically with the medial margin of the trochlea extending further posteriorly on the phalangeal shaft than the correspondent lateral margin. This morphology gives the articulation with the ungual a slight medial orientation. The collateral ligament pits are shallow, well-defined depressions, the lateral of which is deeper than the medial. Both are displaced dorsally. There is no evidence of an extensor pit and the articulation extends only slightly onto the dorsal surface of the element indicating only a marginal degree of extension of the ungual at this joint.

Phalanx III-4 is the ungual phalanx. Like phalanx II-3 it is small and trenchant and a ridge forms the dorsal surface. The articular surface extends dorsally farther than the ventral margin. A prominent flexor tubercle is present near the articular surface as in phalanx II-3 and the other unguals in $\mathrm{Kol}$ ghuva. The axis of symmetry for this ungual is down the midline. Ventrally, the flexor tubercle is positioned offset from the midline laterally. Distal to this the surface, the ungual is weakly arcuate. The medial groove for the claw sheath is positioned ventrally more than the lateral one. The lateral claw-sheath groove deeply incises the surface of the ungual with a dorsally directed flange nearly enclosing the structure near the distal end.

Metatarsal IV is approximately equal in width to MT II in anterior view. The midshaft 
of this element is slightly damaged with portions of the cortex shattered. Unlike other Asian alvarezsaurids, which have MTs II and IV extending distally to an equal extent, $\mathrm{Kol}$ ghuva is characterized by MT VI extending well past the distal margin of MT II. In proximal view MT IV is triangular, narrowest along the anterior margin and expanding posteromedially to terminate in a sharp angle near the contact with MT II. Like the proximal articular surface of MT II, the same surface on MT IV is crenulated, suggesting that the animal had possibly not reached full adulthood. In posterior view, the proximal end of the MT IV is twice the width of MT II. It decreases in width distally becoming subequal to the width of MT II. A weakly developed ridge runs along the posterior margin of the metatarsal. The proximal twothirds of this ridge is located near the midline, but gradually deflects laterally, trending along the lateral extremity of the metatarsal where it terminates just proximal to the articular surface.

The anterior face of MT IV is gently rounded. In cross-section, this metatarsal is subelliptical for most of its length. Beginning near the contact with MT III, MT IV becomes triangular in cross-section as the anterior surface decreases in width but the posterior surface underlies the ventral surface of MT III. The distal articulation is triangular and weakly rounded. Dorsally, there is no flexor pit and lateral collateral ligament pits are absent. Asian alvarezsaurids Shuvuuia deserti (IGM 100/99) and Mononykus olecranus (IGM 107/6) share a distinct lateral flange located dorsally to the lateral flexor ridge that is absent in Kol ghuva and other alvarezsaurids. The ventral flexor ridges are asymmetrically developed with the lateral ridge the largest and posterolaterally directed and the medial ridge simply posteriorly directed. The lateral ridge is sharply defined in profile whereas the medial ridge is shallower and rounded. A shallow sulcus divides the two ridges.

Digit 4 is comprised of five phalanges that progressively decrease in size toward the ungual. As in all other alvarezsaurids, the extensor ridges on the dorsal surfaces of the first four phalanges are very sharply defined and the extensor pits are deep and posteriorly extensive. Phalanx IV-1 is the longest. The proximal articular surface is dorsoventrally tall and oval shaped. The dorsal and ventral surfaces of this structure are equally developed posteriorly. The phalanx is strongly triangular in lateral view where the proximal portion is twice the height of the distal articular surface. The lateral surface is nearly straight and smooth. The medial surface is concave giving the entire phalanx a kinked profile in dorsal view. Ventrally, weak flexor ridges are present. The lateral one is rounded and low whereas the medial ridge is more sharply defined and medially deflected. The distal articulation is weakly ginglymoid and medially slanted. The ventral surface of the articulation is damaged and cannot be characterized. A deep and sharply bounded collateral ligament pit is present and centered on the medial side of the distal portion of the phalanx. No lateral ligament pit is present.

Phalanx IV-2 is approximately two-thirds the length of phalanx IV-1. The proximal articular surface is deeply concave with a distinct dorsal tongue. Also like the preceding phalanx, IV-2 is triangular in lateral profile because of a dorsoventrally expanded proximal articular surface. The ventral surface of the phalanx is flat. A deep circular collateral ligament pit is located on the medial surface of the distal articular surface whereas a very shallow pit is located on the lateral side. Phalanx IV-3 is half the length of IV-2; otherwise in morphology it is nearly identical to its preceding phalanx. Phalanx IV-4 is extremely short. The proximal articular surface is weakly concave and the dorsal margin of the surface does not extend posteriorly to the extent present in the more proximal phalanges. The distal articular surface is not ginglymoid and a dorsal extensor groove is absent. The ventral ridge of the distal articular surface is low and rounded. These ridges are separated by a narrow but deep sulcus.

The ungual of digit 4 is roughly the same length as the ungual of digit 3 . The ventral flexor tubercle is present, but less developed relative to ungual II and III. The ungual of digit 4 is weakly curved and the ventral margin is generally rounded in comparison to the flatter ventral surfaces of unguals II and III. 
Lateral grooves for the claw sheaths are both placed along the ventral margin of the ungual. They are equal in their depth but lack the distinctive twisted morphology present in the other unguals.

Metatarsal V is represented by a short thin splint, which is located along the posterior surface of the main metatarsal body. It is straight, thin, and terminates in a blunt point distally. The proximal end is missing.

\section{DISCUSSION}

Given the unusual size and the extreme arctometatarsalian condition in Kol ghuva, it is necessary to negate assignment to other similar theropods and contemporaneous taxa. Kol ghuva is similar to the oviraptorosaur Avimimus portenosus that is also present in Djadoktha and Barun Goyot localities in the Gobi Desert (Kurzanov, 1981, 1987; Watabe et al., 2006). Specimens have also been recovered in earlier sediments in both Mongolia and China (Currie and Eberth, 1993; see Currie, 2000). Similarities include the presence of an extremely arctometarsalian condition and roughly coequal extension of MT II and IV. However, a defining characteristic of Avimimus portenosus is the coossification of the metatarsals proximally into a tarsometatarsus. This condition led Kurzanov (1981) to originally describe Avimimus portenosus as an avialan. This coossification of the metatarsals (including the distal tarsals) in Avimimus portenosus includes the fifth metatarsal. The proximal ends of MT II and IV are clearly not ossified in Kol ghuva.

The presence of MT I in Kol ghuva clearly distinguishes it from other arctometatarsalian taxa like derived ornithomimids all of which lack the first metatarsal (Makovicky et al., 2004). The primitive ornithomimid Garudimimus brevipes has a well-developed first digit, but is not nearly as arctometatarsalian as Kol ghuva (Barsbold 1981). Even ornithomimids, which lack digit 1, exhibit a much less extreme arctometatarsalian condition than Kol ghuva. For instance in Anserimimus planinychus (Barsbold, 1988) and Gallimimus bullatus (Osmólska et al., 1972), MT III is constricted for the proximal half but is usually visible as a splint of bone in posterior view. MT III is significantly wider than either II or IV and none of the two metatarsals have ginglymoid articulations.

The tyrannosauroid Alectrosaurus olseni (Gilmore, 1933) appears to have a similar metatarsus, especially when the reconstruction of Maleev (1974) is considered. This similarity, however, is only superficial. Examination of the lectotype of Alectrosaurus olseni (AMNH FR 6554) clearly shows that, like other tyrannosaurids, MT III was extensively exposed on the anterior surface of the metatarsus and proximally MT III participated in the ankle joint (Mader and Bradley, 1989). Like other tyrannosauroids but unlike Kol ghuva and all other derived alvarezsaurids, the lateral border of the proximal end of MT II of Alectrosaurus olseni is C-shaped and a small extension of MT III participates in the ankle joint. Additionally, all of the metatarsals of Alectrosaurus olseni are much more robust than those of Kol ghuva and other alvarezsaurids. Given the discussion above and close similarity to other alvarezsaurids, Kol ghuva is clearly a very large alvarezsaurid.

The Ukhaa Tolgod locality includes at least one other alvarezsaurid taxon Shuvuuia deser$t i$, which is known from over 15 specimens, many of which are exceptional (Chiappe et al., 2002). Shuvuuia deserti is also known from the Djadoktha locality of Tugrugyin Shireh (Suzuki et al., 2002) and alvarezsaurids of uncertain affinity have been collected at the following localities: the redbeds of Kheerman Tsav (Norell personal obs.); Bayn Dzak (Norell et al., 1993, 1995); Gilvent Wash (adjacent to the Ukhaa locality); and various lesser-known localities (Norell, personal obs.).

All of the previously known alvarezsaurids are relatively small animals, with an adult size (determined from length of the metatarsus) less than half the size of Kol ghuva. Certainly it also appears that Kol ghuva is less common, given this is the only specimen known from the Ukhaa Tolgod locality, which has been extensively collected and has produced several alvarezsaurid (Shuvuuia deserti) specimens.

As discussed earlier, Kol ghuva is distinguished from other Mongolian alvaezsaurids by other features other than its large size. These features include extensor grooves on 
digit IV phalanges and a robust flexor tubercle on pedal unguals. In the metatarsus, MT III does not reach ankle, MT II is apomorphically shorter than MT IV, and MT II lacks an accessory dorsomedial flange on the medial side of the distal end. Additionally, MT III in Kol ghuva extends proximally more than $1 / 2$ the total metatarsus length, apomorphic for alvarezsaurids.

\section{CONCLUSIONS}

The holotype specimen of Kol ghuva (IGM 100/2011) provides evidence of a previously unknown element of the rich Ukhaa Tolgod dinosaurian assemblage (Dingus et al., 2008). The incompleteness of the type material of $\mathrm{Kol}$ ghuva provides little in the way of morphological characteristics helpful in the illumination of the phylogenetic relationships within the group, although presence of an extreme arctometatarsus clearly demonstrates it to be more derived than either Alvarezsaurus calvoi or Patagonykus puertai. A close inspection of the morphology of Kol ghuva does document a previously unutilized variation that appears characteristic of the most derived Asian alvarezsaurids. This variation includes the dorsally placed flange on the lateral side of MT IV (present in Shuvuuia deserti IGM 100/ 1276 and Mononykus olecranus IGM 107/6). Also shared among these Asian alvarezsaurids, and possibly more basal alvarezsaurids (e.g., Patagonykus puertai MCP PVPH 37), is the development of deep and proximally expanded extensor pits on the phalanges of digit 4. Ultimately, this character after subjected to the test of congruences may prove to be synapomorphic for Alvarezsauridae.

\section{ACKNOWLEDGMENTS}

We thank the National Science Foundation (DEB 0228693 and ATOL 0228693) for supporting this project. Fieldwork for this project was conducted under the auspices of the Mongolian Academy of SciencesAmerican Museum of Natural History Paleontological Project and we would like to thank the members of the hard-working 2000 field season. Jim Klausen is thanked for the initial preparation of the specimen. Mick
Ellison skillfully prepared the figures. Two anonymous reviewers significantly improved the paper. Additional financial support for AHT and SJN was provided by the Division of Paleontology at the American Museum of Natural History and the Department of Earth and Environmental Sciences of Columbia University.

\section{REFERENCES}

Barsbold, R. 1981. The toothless carnivorous dinosaurs of Mongolia. Sovmestnaya SovetskoMongolskaya Paleontologichekaya Ekspeditsia Trudy 15: 28-39. [In Russian]

Barsbold, R. 1988. A new Late Cretaceous ornithomimid from the Mongolian People's Republic. Paleontological Journal 22: 124-127.

Bonaparte, J.F. 1991. Los vertebrados fosiles de la Formacion Rio Colorado, de la ciudad de Neuquen y cercanias, Cretacico Superior, Argentina. Revista Museo Argentino Ciencias Naturales "Bernardino Rivadavia" Paleontologia 4: $17-123$.

Chiappe, L., M.A. Norell, and J.M. Clark. 1996. Phylogenetic position of Mononykus (Aves: Alvarezsauridae) from the Late Cretaceous of the Gobi Desert. Memoirs of the Queensland Museum 39: 557-582.

Chiappe, L.M., M.A. Norell, and J.M. Clark. 1998. The skull of a relative of the stem-group bird Mononykus. Nature 392: 275-278.

Chiappe, L.M., M.A. Norell, and J.M. Clark. 2002. The Cretaceous, short-armed Alvarezsauridae: Mononykus and its kin. In: L.M. Chiappe and L. Witmer (editors), Mesozoic birds: above the heads of dinosaurs. Berkeley: University of California Press, 87-120.

Clark, J.M., M.A. Norell, and L.M. Chiappe. 1999. An oviraptorid skeleton from the Late Cretaceous of Ukhaa Tolgod, Mongolia, preserved in an avian-like brooding position over an oviraptorid nest. American Museum Novitates 3265: 1-36.

Currie, P.J. 2000. Theropods from the Cretaceous of Mongolia. In: M.J. Benton, M.A. Shishkin, D.M. Unwin and E.N. Kurochkin (editors), The age of dinosaurs in Russia and Mongolia. Cambridge: Cambridge University Press, $434-455$.

Currie, P.J., and D.A. Eberth. 1993. Palaeontology, sedimentology and palaeoecology of the Iren Dabasu Formation (Upper Cretaceous), Inner Mongolia, People's Republic of China. Cretaceous Research 14: 127-144.

Dashzeveg, D., M.J. Novacek, M.A. Norell, J.M. Clark, L.M. Chiappe, A. Davidson, M.C. 
McKenna, L. Dingus, C. Swisher, and A. Perle. 1995. Unusual preservation in a new vertebrate assemblage from the Late Cretaceous of Mongolia. Nature 374: 446-449.

Dingus, L., D.B. Loope, D. Dashzeveg, C.C. SwisherIII., C. Minjin, M.J. Novacek, and M.A. Norell. 2008. The geology of Ukhaa Tolgod (Djadokhta Formation, Upper Cretaceous, Nemegt Basin, Mongolia). American Museum Novitates 3616: 1-40.

Gauthier, J.A. 1986. Saurischian monophyly and the origin of birds. Memoirs of the California Academy of Sciences 8: 1-55.

Gilmore, C.W. 1933. On the dinosaurian fauna of the Iren Dabasu Formation. Bulletin of the American Museum of Natural History 67(2): 23-78.

Huene, F.v. 1914. Das naturliche System der Saurischia. Centralblan für Mineralogie, Geologie und Paleontologie Jahrgang Abteilung B5: 154-158.

Hutchinson, J.R., and L.M. Chiappe. 1998. The first known alvarezsaurid (Theropoda: Aves) from North America. Journal of Vertebrate Paleontology 18: 447-450.

Karhu, A.A., and A.S. Rautian. 1996. A new family of Maniraptora (Dinosauria: Saurischia) from the late Cretaceous of Mongolia. Paleontological Journal 30: 583-592.

Kurzanov, S.M. 1981. [On the unusual theropods from the Upper Cretaceous of Mongolia]. Sovmestnaya Sovetsko-Mongolskaya Paleontologichekaya Ekspeditsia Trudy 15: 39-50. [In Russian, English summary]

Kurzanov, S.M. 1987. [Avimimids and the problem of the origin of birds]. Sovmestnaya SovetskoMongolskaya Paleontologichekaya Ekspeditsia Trudy 31: 5-95. [In Russian]

Longrich, N.R., and P.J. Currie. 2009. Albertonykus borealis, a new alvarezsaur (Dinosauria:Theropoda) from the Early Maastrichtian of Alberta, Canada: implications for the systematics and ecology of Alvarezsauridae. Cretaceous Research 30: 239-252.

Mader, B.J., and R.L. Bradley. 1989. A redescription and revised diagnosis of the syntypes of the mongolian tyrannosaur Alectosaurus olseni. Journal of Vertebrate Paleontology 9: 41-55.

Makovicky, P.J., Y. Kobayashi, and P.J. Currie. 2004. Ornithomimosauria. In: D. Weishampel, P. Dodson and H. Osmolska (editors), The Dinosauria. 2nd ed. Berkeley: University of California Press, 137-150.

Maleev, E.A. 1974. Gigantic carnosaurs of the family Tyrannosauridae. Joint Soviet-Mongolian Paleontological Expedition Transactions 1: 132-191. [In Russian]
Marsh, O.C. 1884. Principal characters of American Jurassic dinosaurs. Part 8. The Order Theropoda. American Journal of Science (3) 27: 329-340.

Martinelli, A., and E.I. Vera. 2007. Achillesaurus manazzonei, a new alvarezsaurid theropod (Dinosauria) from the Late Cretaceous Bajo de la Carpa Formation, Río Negro Province, Argentina. Zootaxa 1582: 1-17.

Naish, D., and G.J. Dyke. 2004. Heptasteornis was no ornithomimid, troodontid, dromaeosaurid or owl: the first alvarezsaurid (Dinosauria: Theropoda) from Europe. Neues Jahrbuch für Geologie und Paläontologie Monatshefte 7: 385-401.

Norell, M.A., L.M. Chiappe, and J.M. Clark. 1993. New limb on the avian family tree. Natural History 9/93: 38-43.

Norell, M.A., L. Dingus, and E.S. Gaffney. 1995. Discovering dinosaurs. New York: Knopf, $225 \mathrm{pp}$.

Norell, M.A., and P.J. Makovicky. 1999. Important features of the dromaeosaurid skeleton. 2. Information from newly collected specimens of Velociraptor mongoliensis. American Museum Novitates 3282: 1-45.

Novas, F.E. 1996. Alvaresauridae, Cretaceous maniraptorians from Patagonia and Mongolia. Memoir of the Queensland Museum 39: 675-702.

Novas, F.E. 1997. Anatomy of Patagonykus puertai (Theropoda, Maniraptora, Alvarezsauridae). Journal of Vertebrate Paleontology 17: 137166.

Osmolska, H., E. Roniewicz, and R. Barsbold. 1972. A new dinosaur, Gallimimus bullatus n. gen., n. sp. (Ornithmimidae) from the Upper Creaceous of Mongolia. Palaeontologica Polonica 27: 103-143.

Perle, A., L.M. Chiappe, J.M. Clark, R. Barsbold, and M.A. Norell. 1994. Skeletal morphology of Mononykus olecranus (Theropoda: Avialae) from the Late Cretaceous of Mongolia. American Museum Novitates 3105: 1-29.

Perle, A., M.A. Norell, L.M. Chiappe, and J.M. Clark. 1993. Flightless bird from the Cretaceous of Mongolia. Nature 362: 623-626.

Schweitzer, M.H., J.A. Watt, R. Avci, L. Knapp, L. Chiappe, M.A. Norell, and M. Marshall. 1999. Beta-keratin specific immunological reactivity in feather-like structures of the Cretaceous alvarezsaurid, Shuvuuia deserti. Journal of Experimental Zoology 285: 146-157.

Sereno, P.C. 2001. Alvarezsaurids: birds or ornithomimosaurs? In: J. Gauthier and L.F. Gall (editors), New perspectives on the origin and early evolution of birds; proceedings of the international symposium in honor of John $\mathrm{H}$. 
Ostrom. New Haven, CT: Yale Peabody Museum, 69-98.

Suzuki, S., L.M. Chiappe, G.J. Dyke, M. Watabe, R. Barsbold, and K. Tsogbaatar. 2002. A new specimen of Shuvuuia deserti Chiappe et al. 1998, from the Mongolian Late Cretaceous with a discussion of the relationships of Alvarezsaurids to other theropod dinosaurs. Natural History Museum of Los Angeles County Contributions in Science 494: 1-18.

Turner, A.H., D. Pol, J.A. Clarke, G.M. Erickson, and M.A. Norell. 2007. Basal-most dromaeo-

\section{APPENDIX 1}

\section{InStitutional AbBreViations}

AMNH FR American Museum of Natural History, New York, USA. Fossil Reptiles and Amphibians

IGM saurid demonstrates miniaturization preceded avian flight. Science 317: 1378-1381.

Watabe, M., S. Suzuki, and K. Tsogbataar. 2006. Geological and geographical distribution of bird-like theropod, Avimimus in Mongolia. Journal of Vertebrate Paleontology 26(suppl. to 3$): 136$.

Xu, X., J.M. Clark, C.A. Forster, M.A. Norell, G.M. Erickson, D.A. Eberth, C. Jia, and Q. Zhao. 2006. A basal tyrannosauroid dinosaur from the Late Jurassic of China. Nature 439: 715-718.

MACN Museo Argentino de Ciencias Naturales, "B. Rivadavia," Buenos Aires, Argentina

MAE Mongolian American Expedition MCF Museo Municipal "Carmen Funes," Plaza Huincul, Neuquén, Argentina

MUC Museo de Ciencias Naturales, Universidad Nacional del Comahue, Neuquén, Argentina 

Complete lists of all issues of the Novitates and the Bulletin are available at World Wide Web site http://library.amnh.org/pubs. Inquire about ordering printed copies via e-mail from scipubs@amnh.org or via standard mail from: American Museum of Natural History, Library-Scientific Publications, Central Park West at 79th St., New York, NY 10024. TEL: (212) 769-5545. FAX: (212) 769-5009. 